\title{
Изучение влияния граничных эффектов на плазмонную силу между металлическими пластинами
}

\author{
$\underline{\text { А.К. Туснин }}^{1, *}$, Л.Л. Фрумин ${ }^{1,2}$, Д.А. Шапиро ${ }^{1,2}$ \\ ${ }^{1}$ Институт автоматики и электрометрии СО РАН \\ ${ }^{2}$ Новосибирский государственный технический университет \\ *E-mail: alextusnin@gmail.com
}

DOI: 10.31868/RFL2020.230-231

Использование светоиндуцированных сил для манипуляции микро- и нанообъектами имеет широкий спектр применений в различных областях, включая как Микро-Опто-Электро-Механические системы (англ. MOEMS) [1], изучение биологических и макро-молекулярных систем [2,3]. Одним из основных инструментов в этой области являются плазмонные силы [1], которые позволяют манипулировать диэлектрическими объектами. В 2011 году Нестеров и др. обнаружили новый тип светоиндуцированных сил, которые позволяют манипулировать металлическими микро- и нано-частицами [4]. Авторы обнаружили, что при возбуждении поверхностного плазмона между двумя металлическими пластинами, в зазоре возникает сила притяжения. В связи с этим, эта сила была названа плазмонной. Последующие теоретические работы исследовали влияние неточности юстировки и высших мод на величину силу, предполагая размер пластин и фронт падающего излучения бесконечными $[5,6]$. В данной работе мы рассматриваем эффекты конечной фокусировки и ширины пластин.

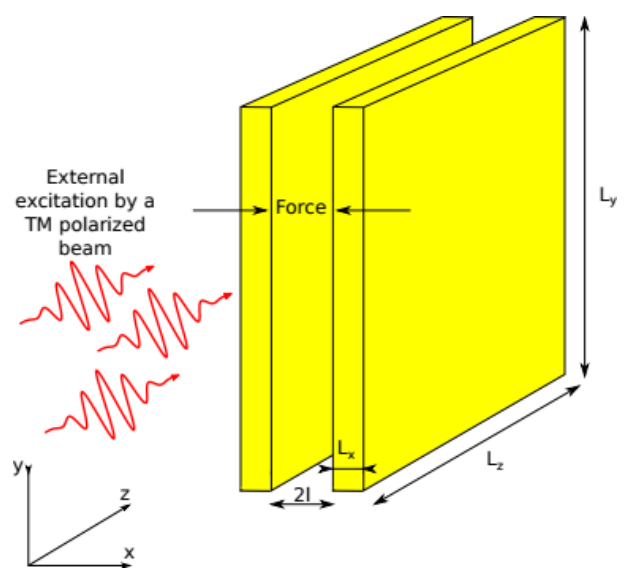

Рис. 1. Геометрия задачи. Падающее излучение имеет компоненту магинтного поля только вдоль оси у.

Мы рассматриваем две параллельные металлические пластины с диэлектрической проницаемостью $\varepsilon=\varepsilon_{1}+\mathrm{i} \varepsilon_{2}$ на расстоянии 21 друг от друга. Пренебрегая высотой $\left(\mathrm{L}_{\mathrm{y}}\right)$ и толщиной $\left(\mathrm{L}_{\mathrm{x}}\right)$ пластин и рассматривая только нормальное падение падающего излучения на переднюю грань (см. Рис. 1), мы изучали по отдельности эффекты цилиндрической (вдоль оси х), сферической (вдоль осей х и у) фокусировок, а так же влияние конечной ширины $\left(\mathrm{L}_{z}\right)$ пластин. Для расчёта возникающей силы мы интегрировали тензор натяжений Максвелла по внутренней поверхности пластин. Однако, для этого необходимо знать распределение электро-магнитного (ЭМ) поля внутри щели. Для расчёта ЭМ поля 
мы использовали разложение на собственные функции, которое позволило нам свести уравнение гельмгольца на у-компоненту магнитного поля к системе линейных уравнений на амплитуды возбуждаемых мод.

В ходе расчётов было установлено, что цилиндрически сфокусированный пучок может возбуждать высшие моды внутри щели, что ведёт к уменьшению возникающей силы, так как лишь фундаментальная мода вызывает притяжение. Расчёт в случае сферической фокусировки был произведён для субволновой ширины щели, когда лишь фундаментальная мода существует в резонаторе. Было показано, что сила пропорциональна ширине пучка. При анализе влияния ширины пластин мы рассматривали фундаментальные моды, распространяющиеся вдоль и против направления падения. Было получена резонансная зависимость силы от ширины пластин при разных значениях ширины щели. В случае очень узкой щели резонансное значение силы может быть больше, чем для бесконечно больших пластин, однако резонансы в этом случае очень узкие. С увеличением ширины щели, резонансы сглаживаются и сила равномерно растёт с увеличением ширины пластин.

Полученные результаты могут быть использованы для подготовки и реализации эксперимента по измерению плазмонной силы с использованием средств микрофабрикации.

\section{Литература}

[1] M.E. Motamedi, Optical Engineering 33(11), 3505-3518 (1994)

[2] A. Ashkin and J.M. Dziedzic, Science 235, 1517-1520 (1987)

[3] D.G. Grier, Nature 424, 810-816 (2003)

[4] V. Nesterov, L. Frumin and E. Podivilov, EPL 94, 64002 (2011)

[5] L.L. Frumin, A.K. Tusnin, O.V. Belai, D.A. Shapiro, Opt. Express 25, 31801-31809 (2017)

[6] A. Tusnin, D. Shapiro, OSA Continuum 1, 384-391 (2018)

Научный руководитель - доктор физ.-мат. наук Д.А. Шапиро 